\title{
O SIGNIFICADO DA APOSENTADORIA PARA PESSOAS APOSENTADAS DE UM ÓRGÃO PÚBLICO
}

The meaning of retirement for retired people from a public body

Le sens de la retraite pour les personnes retraités d'un organisme public

El significado de la jubilación para los jubilados de un organismo público

Carla Sabrina Antloga1

Doutora em Psicologia Social, do Trabalho e das Organizações, com ênfase em Ergonomia da Atividade Aplicada à Qualidade de Vida no Trabalho - EAAQVT (PSTO-UnB). Professora Adjunta do Departamento de

Psicologia Social e do Trabalho na Universidade de Brasília. Coordenadora do Curso de Graduação em Psicologia da UnB. Coordenadora do Grupo de Estudos em Psicodinâmica do Trabalho Feminino, vinculado ao Laboratório de Psicodinâmica e Clínica do Trabalho - LPCT (Instituto de Psicologia, UnB)

Solene Nobre de Medeiros ${ }^{2}$

Mestre em Psicologia Social, do Trabalho e das Organizações pela Universidade de Brasília. Especialista em

Psicologia Clínica e Psicologia do Trânsito pelo Conselho Federal de Psicologia. Especialista em Teoria Psicanalítica e em Psicodinâmica do Trabalho pela Universidade de Brasília (UnB). Graduada em Letras e em Psicologia. Servidora pública, psicóloga clínica e clínica do trabalho. Coordenadora do Programa de Preparação para Aposentadoria do DETRAN

Rebeca Moreira
Graduação em Letras pela Universidade de Brasília - UnB (2006). Atualmente, cursa graduação em Psicologia
na Universidade de Brasília. É servidora Pública na área de Educação para o Trânsito.

Marina Maia ${ }^{4}$ Mestre em Psicologia Social, do Trabalho e das Organizações (PG-PSTO, UnB). Psicóloga e bacharela em psicologia (UnB). Profes sora substituta no departamento de Psicologia Social e do Trabalho (PST - UnB).

Professora no Centro Universitário Projeção.

\section{RESUMO}

Esta pesquisa objetivou compreender o significado da aposentadoria para pessoas aposentadas de um órgão público. Participaram 24 servidores (as) aposentados (as). Realizaram-se entrevistas individuais com roteiro semiestruturado. Os dados foram tratados por meio da Semiótica. Os resultados indicam significantes positivos em relação à percepção da aposentadoria para os aposentados, como liberdade e merecimento. Já os significantes da percepção social da aposentadoria na visão dos aposentados indicam aspectos negativos como inatividade e invalidez, além de apontamentos em relação à velhice. Sendo as sim, a forma como os outros veem a aposentadonia é mais negativa do que o significado da aposentadoria para os próprios participantes.

Palavras-chave: aposentadoria, semiótica, ergonomia da atividade.

\footnotetext{
1 E-mail: antlogacarla@gmail.com

2 E-mail: solenenobre@globo.com

3 E-mail: rebecaunb@gmail.com

4 E-mail: m.maiacarmo@gmail.com
} 


\begin{abstract}
This research aimed to understand the meaning of retirement for retired people from a public body. Twenty-four retired servers participated. Individual interviews were conducted with a semi-structured script. The data were treated through Semiotics. The results indicate positive significance regarding the perception of retirement for retirees, such as freedom and merit. On the other hand, the significance of social perception of retirement in the view of retirees indicate negative aspects such as inactivity and disability, as well as notes regarding old age. Thus, the way others view retirement is more negative than the meaning of retirement for the participants themselves.
\end{abstract}

Keywords: retirement, Semiotics, activity ergonomics.

\title{
RÉSUMÉ
}

Cette recherche visait à comprendre le sens de la retraite pour les personnes retraités d'un organisme public. 24 employés retraités ont participé. Entretiens individuels ont été menés avec une feuille de route semi-structuré. Les données ont été traitées par le sémiotique. Les résultats indiquent signifiants positifs en ce qui concerne la perception de la retraite pour les retraités, tels que la liberté et le mérite. D'autre part, la perception sociale de la retraite dans la vue des retraités indiquent aspects négatifs tels que l'inactivité et de l'invalidité, ainsi que les notes relatives à la vieillesse. Alors, comment les autres voient la retraite est plus négatif que le sens de la retraite pour les participants eux-mêmes.

Mots-clés: la retraite, l'analyse du discours, l'activité de l'ergonomie.

\section{RESUMEN}

Esta investigación tuvo como objetivo comprender el significado de la jubilación para jubilados de un organismo público. 24 empleados jubilados participaron. Entrevistas individuales con guión semiestructurado se llevaron a cabo. Los datos fueron procesados a través del Semiótica. Los resultados indican significantes positivos con respecto a la percepción de la jubilación para los jubilados, como la libertad y el mérito. Por otro lado, los significantes de la percepción social de la jubilación a la vista de los jubilados indican aspectos negativos como la inactividad y la discapacidad, así como las notas en relación con la vejez. Por lo tanto, la forma en que otros ven la jubilación es más negativo que el significado de la jubilación para los propios participantes.

Palabras clave: jubilación, semiótica, actividad de la ergonomía.

\section{INTRODUÇÃO}

Este estudo objetivou compreender o significado da aposentadoria para servidores aposentados e identificar, por meio de seus discursos, a percepção que eles têm sobre ser aposentado, bem como a percepção da sua imagem de aposentados para a sociedade.

A aposentadoria pode ser compreendida como um fenômeno social e econômico de afastamento do sistema de produção (Santos, 1990). No cenário brasileiro, a questão da aposentadoria ocorre em um contexto de aumento sistemático da população idosa. De acordo com dados do IBGE (Instituto Brasileiro de Geografia e Estatística), a população de idosos no Brasil foi de 7,38\% em 2010. Tal população aumentou em 1,53\% nos últimos dez anos e deve triplicar nos próximos 20 anos (IBGE, 2013).

A maneira como a cultura lida com a velhice é o retrato da própria comunidade de maneira que "o sentido ou o não sentido de que se reveste a velhice no seio de uma sociedade coloca toda essa sociedade em questão" (Beauvoir, 1990, p.16). O papel atribuído à idade é determinante para o comportamento social diante da velhice em relação a sua própria percepção da tomada de tempo e em relação a outras pessoas.

A autora supracitada afirma que a velhice é o destino que se apodera do sujeito, o qual é surpreendido quando o grupo social o posiciona no lugar do idoso (Beauvoir, 1990). A surpresa do envelhecer está nos sentidos atribuídos à velhice como o lugar da impotência, da improdutividade 
e das deficiências que a torna aversiva para muitas pessoas.

A aposentadoria pode ser analisada com base nos níveis individual, organizacional e social, assim como com base em variáveis que podem influenciar em termos de antecedentes e consequentes (Beehr \& Bennert, 2007). No nível individual, busca-se compreender como a história pessoal e as características individuais tornam a aposentadoria mais ou menos desejada e como os indivíduos são impactados por ela. No nível organizacional, busca-se compreender $\mathrm{o}$ quanto a organização influencia positiva ou negativamente na decisão de aposentar-se. No terceiro nível, analisam-se as questões sociais que impactam na aposentadoria como, por exemplo, a necessidade de se manter por mais tempo no mercado de trabalho ou, ao contrário, a decisão de se aposentar mais cedo, deixando as vagas para outros trabalhadores.

Para Atchley (1999), as vivências da aposentadoria são heterogêneas e o ajustamento ou não a essa situação está associado à posição do trabalho na hierarquia pessoal do sujeito, assim como ao alcance dos objetivos relacionados ao trabalho. Para o autor, o processo de aposentadoria é um momento de transição em que ocorre o abandono do papel profissional e a construção da identificação com o papel de aposentado.

Da mesma forma, os estudos de Rodrigues, Ayabe, Lunardelli e Canêo (2005) e Wang, Henkens e Solinge (2011) indicam as diferenças e a heterogeneidade quanto às vivências da aposentadoria, apontando a importância de ampliação de pesquisas sobre o tema.

De acordo com Wang et al. (2011), a aposentadoria abarca processos de perdas e enfraquecimento de papéis relacionados ao trabalho e, em contrapartida, o fortalecimento do papel de membro da família e da comunidade. Uvaldo (1995) destaca, em seus estudos, o status ocupado pelo trabalhador na empresa; o poder exercido sobre outras pessoas; a estabilidade financeira e a própria rotina enquanto referencial de existência como possíveis perdas decorrentes da aposentadoria.

Referente à percepção social da aposentadoria, Santos (1990) ressalta a aposentadoria como a entrada oficial na velhice, considerando a dinâmica das sociedades industriais modernas. León (1999) aponta a aposentadoria como um indicador temporal de envelhecimento - e, por conseguinte, conferindo um caráter de inutilidade ao indivíduo aposentado. Nesse mesmo sentido, França (2003) destaca as representações pejorativas - em algumas culturas - associadas aos idosos como sendo velhos e ultrapassados.

Segundo França, Murta, Negreiros, Pedralho e Carvalhedo (2013), a aposentadoria representa para alguns trabalhadores a chance de concretizar projetos que não foram possíveis devido ao tempo dedicado ao trabalho. Para tais indivíduos, o trabalho estava atrelado ao sentido de opressão, sendo a aposentadoria vivenciada como liberdade e sentimento de alívio. Esse achado dialoga com as exposições de Wang et al. (2011), ao afirmarem que a aposentadoria é tida como uma possibilidade de saída de tensões e conflitos em trabalhos desagradáveis e/ou estressantes, configurando-se como uma forma de alívio.

O processo de transição para a aposentadoria pode ser descrito pelo seu modo abrupto ou gradual de ocorrer e pelo grau de controle que o indivíduo tem sobre a transição. (Vaus, Wells, Kending \& Quine, 2007). Em estudo realizado com trabalhadores australianos, verificou-se a não diferenciação em termos de efeitos entre uma aposentadoria abrupta rompimento brusco com o trabalho sem a perspectiva de volta ao mercado profissional - e gradual - quando os trabalhadores se afastam progressivame nte da prática do trabalho ou retornam ao trabalho com diminuição da jornada. No entanto, destaca-se a relevância do controle do tempo e do modo de deixar o trabalho, 
que exercem impactos positivos no bemestar psicológico e social.

Para Santos (1990), a aposentadoria caracteriza-se por uma dinâmica psicossocial no sentido da reorganização da identidade pessoal e social em consequência da perda de um papel social que se estabelecia com o trabalho. Já em relação ao estudo da análise de metáforas relacionadas ao significado da aposentadoria, Sargent, Bataille, Vough e Lee (2011, pp. 320-321, tradução nossa) identificaram quatro significados atribuídos à aposentadoria:

a) Explorar novos horizontes - a aposentadoria é caracterizada por excitação, exploração, engajamento a novas atividades, autodescoberta e autodesenvolvimento. Neste caso, a aposentadoria é vista como um novo começo;

b) Procurar por um significado - a aposentadoria é vista, em princípio, como uma perda de valor para a sociedade e há comprometimento da identidade, visto que o trabalho funcionava como um guia, provendo ao indivíduo trabalhador os propósitos, status e identidade. Nessa perspectiva, o aposentado ainda não encontrou um sentido para si mesmo e para as rotinas da aposentadoria;

c) Contribuir a seu modo - Os aposentados mantêm a identidade profissional, engajando-se em atividades profissionais a seu modo, detendo maior gestão do próprio estilo de vida;

d) Tempo de relaxar - A aposentadoria é caracterizada como a oportunidade de retomar o controle, autonomia e liberdade face a uma rotina opressiva de trabalho. Essa liberdade é entendida como uma recompensa e uma oportunidade de se engajar em atividades que foram impossibilitadas pelo trabalho de tempo integral.
De acordo com Tolfo e Piccinini (2007), o trabalho assume sentido em nível individual e social, constituindo-se como um dos aspectos estruturadores da identidade e da subjetividade. As autoras pontuam que o significado do trabalho pode ser compreendido como "a representação social que a tarefa executada tem para o trabalhador" (p.40), seja para o indivíduo, para o grupo ou socialmente. Codo (1996) indica que a relação entre o homem e o objeto, representada pelo trabalho, consiste numa transformação recíproca do trabalho da qual emergem significados que permanecem para além desta relação, ou seja, os significados, qualificações, acepções se mantêm mesmo com a dissolução da relação. Para o autor, o rompimento desta relação de transformação mútua tem como consequência o sofrimento do trabalhador.

Em interface de estudo relativo à área do trabalho destaca-se a Ergonomia da Atividade, que se fundamenta na relação indivíduo-ambiente mediada pela atividade de trabalho. Nessa perspectiva, o indivíd uo, ao transformar o ambiente, também sofre modificações por meio de sua própria ação (Ferreira, 2003).

$\mathrm{O}$ trabalho tem função social significativa, mas envolve mudanças na subjetividade. Segundo Guérin et al. (2001), o significado da atividade de trabalho para o indivíduo, "ao concretizar-se no resultado, impregna de sentido sua relação com o mundo, fator determinante da construção de sua personalidade e de sua socialização" (p.18). Nesse sentido, importa lembrar que o sujeito forja o trabalho, mas também é "forjado" por ele (Ferreira, 2003), assim, modifica-se para o trabalho e pelo trabalho. Por essa razão, o deixar de trabalhar pode gerar para o trabalhador um impacto maior do que se imagina.

A atividade de trabalho para Guérin, Laville, Daniellou, Duraffourg e Kerguelen (2001) é "a estratégia de adaptação do trabalhador à situação real de trabalho" (p.15) frente às condições do trabalhador e à prescrição do trabalho. Portanto, é a 
resposta de ação diante do trabalho prescrito e as contradições que promovem uma lacuna entre o sujeito e a conjuntura real (Abrahão, Sznewar, Silvino, Sarmet, \& Pinho, 2009).

Diante do exposto, este estudo tem como base teórico-metodológica a Ergonomia da Atividade que vê a atividade de trabalho como central na constituição e vivência do indivíduo. Neste sentido, a aposentadoria traria diversas repercussões para o indivíduo, posto que ele não mais se significaria pela atividade realizada. Pressupõem-se, então, implicações no que tange à subjetividade, à identidade e à dinâmica psicossocial do indivíduo como um todo. Para a Ergonomia da Atividade, um método se faz pertinente se está em função dos objetivos que pretende alcançar e da realidade que se propõe apreender. Dessa forma, pode-se fazer uso de diferentes métodos, desde que subordinados ao objetivo.

Esse estudou baseou sua análise na perspectiva da semiótica que investiga a linguagem nas suas diversas formas de se fazer sentido. Compreendendo-se que a linguagem apresentada nos discursos, assim como definida por Luria (1994), é a representação da realidade introjetada pelo social, é que se optou pela análise semiótica dos discursos, entendendo que os signos, significados e significantes conduzem a representação do mundo que é social e ao mesmo tempo subjetiva. Fontanille (2007) define o sentido como a direção de um texto e, consequentemente, como a matéria da qual a semiótica ocupa-se. $\mathrm{O}$ sentido contém a natureza física, psicológica, social e cultural da matéria. Além do sentido, a semiótica dispõe de mais dois termos: a significação e a significância. A significação, para o autor, compreende a inerência do conteúdo de uma unidade e articula-se com o sentido, já a significância compreende a "globalidade dos efeitos do sentido" (p.32).

Outra distinção necessária é a de semiótica e semântica que, apesar de se parecerem, segundo Fontanille (2007), a primeira "liga o sentido das unidades da língua e sua expressão morfológica e lexical" (p.33) e a segunda está na ordem do discurso, na "significação dos enunciados" (p.33). Essa distinção é necessária, pois na análise dos dados são considerados os planos da expressão e o plano do conteúdo da linguagem, considerando os aspectos internos e externos do enunciador.

Para Fiorin (2012), o acesso à realidade é mediado pela linguagem, de maneira que "o discurso não se constrói sobre a realidade, mas sobre outro discurso" (p.146) apontando o caráter histórico e social que se apresentam no discurso. O autor ressalta que o discurso está no plano do conteúdo e se concretiza por meio do texto. Enquanto o discurso torna presente o que está ausente, o texto manifesta o discurso e é por meio do texto que há o acesso à realidade.

Fiorin (2012) aponta, ainda, que "o discurso ganha sentido e identidade na relação com outros discursos" (p.151). É o dialogismo do discurso que dá o seu caráter histórico e é nele que se apresenta a representação de um fenômeno social. Assim, pretende-se, por meio da análise dos discursos pela semiótica, compreender o significado da aposentadoria para os participantes da pesquisa.

\section{Método}

\section{Contexto da pesquisa}

A pesquisa foi realizada com servidores públicos aposentados de um órgão do Distrito Federal. A instituição é uma entidade autárquica de administração indireta, cujos objetivos principais são dirigir, fiscalizar, controlar e executar os serviços relativos ao trânsito (Brasília, 2011).

A pesquisa resultou do levantamento de informações para subsidiar o desenvolvimento do Programa de Preparação para a Aposentadoria (PPA) da instituição. As entrevistas foram realizadas no período entre novembro e dezembro de 2013. 


\section{Participantes}

Participaram da pesquisa 24 servidores aposentados, com idades entre 37 e 82 anos $(M=59,54$ e $D P=7,98)$, sendo 11 do gênero feminino e 13 do gênero masculino.

\section{Instrumento}

Para a coleta dos dados, foi utilizado como instrumento de pesquisa uma entrevista semiestruturada. Esse tipo de entrevista combina perguntas fechadas e perguntas abertas, de forma que $o$ entrevistado discorra acerca do tema sem se prender exclusivamente às questões formuladas. Tal instrumento é umas das ferramentas mais utilizadas nas investigações de trabalhos de campo, pois permite a construção de informações importantes do objeto de pesquisa com riqueza de detalhes, bem como alcance de dados válidos (Minayo, 2013).

As questões das entrevistas contemplaram duas temáticas centrais: $\left(1^{\mathrm{a}}\right)$ o que $o$ entrevistado pensa sobre a aposentadoria e ( $\left.2^{\mathrm{a}}\right)$ qual, na sua visão, é a imagem do aposentado para a sociedade. Dados demográficos, tais como idade, sexo, tempo de serviço, também foram coletados.

\section{Procedimentos}

O contato para a participação na pesquisa ocorreu via telefone ou pessoalmente e foi realizado pelo núcleo de aposentadoria e pensão da instituição. Foram convidados para participar da pesquisa servidores aposentados, os quais poderiam ter ou não retornado à antiga atividade de trabalho, e servidores que poderiam aposentar-se em um período de até 2 anos. Não houve preferência por gênero e cargo de ocupação. Para as entrevistas não houve seleção da vivência na aposentadoria, para esse estudo, no entanto, consideramos apenas as entrevistas com servidores aposentados.

\section{Análise de dados}

Esta pesquisa qualitativa foi realizada pela análise semiótica dos textos discursivos apresentados pelos participantes nas suas representações sobre aposentadoria, seja no discurso a respeito deles mesmos, seja na questão social da aposentadoria. Nessa abordagem de análise, baseada em Fiorin (2005), o discurso é constituído por elementos sintáticos e semânticos, porém, para realizar as discussões, este estudo limitou-se ao nível fundamental das categorias de oposição, que ligam o objeto aos seus vários predicados: os subjetivos, a partir do discurso que volta para si, e os sociais, que partem do discurso de si a partir da perspectiva do outro.

Com base na concepção dialógica da análise do discurso de Fiorin (2005), os significantes foram divididos em categorias opositivas conjuntivas e disjuntivas revelando as contradições relativas à representação de aposentadoria, para as duas temáticas orientadoras da entrevista. Os campos semânticos que mais se repetiam foram analisados revelando um sentido comum dado à aposentadoria e foram analisados conforme a estrutura em que se apresentavam.

\section{Resultados e discussão}

De acordo com os estudos de Leão (1999), a linguagem, além de mediar as relações, permite conhecer os aspectos essenciais do pensamento. Quando o discurso verbaliza a percepção social de um aspecto da vida, traduz a representação desse aspecto e o sofrimento que pode gerar.

Neste estudo, os resultados obtidos no nível fundamental dos discursos podem ser analisados por meio de categorias de oposição disjuntivas e conjuntivas em relação ao sentido da aposentadoria, à percepção social da aposentadoria, além das características da aposentadoria que interseccionam o sentido pessoal e social. 
Segundo Fiorin (2005), "uma categoria semântica fundamenta-se numa diferença, oposição" (p. 21), assim, os dados trazem as categorias para análise sob a perspectiva que ora é disfórica, com valor negativo, ora é eufórica, com valor positivo adquirindo múltiplas perspectivas.

Em relação ao que os trabalhadores aposentados pensam sobre a aposentadoria, identificou-se o número de 75 significantes no sentido de: recompensa, prêmio, liberdade, tempo para realizar atividades, fazer o que gosta, descanso, sossego, ausência de preocupações com a rotina laboral, estar ativo, viagens, ter tempo para relacionar-se com outras pessoas. Foram encontrados 20 significantes no sentido de: diminuição salarial, falta de orgulho, perda de amigos, adaptação à transição, ficar encostado, fim da vida, invalidez, angústia, ansiedade e depressão.

\section{Aposentadoria como Liberdade}

A aposentadoria significando liberdade foi manifesta em grande parte dos discursos e pode ser exemplificada pelas falas:

1"estou me sentindo livre, livre (...) assim, solta, sabe?", 2"aposentadoria é a liberdade" e 3"assinei a alforria". A primeira fala, a liberdade do tempo presente, presentifica a não liberdade de outro tempo, aquele tempo contrário à aposentadoria, ou seja, o tempo de trabalho. Assim, aposentadoria e trabalho aparecem em oposição, bem como liberdade e não liberdade. A segunda fala conceitua aposentadoria de maneira geral como liberdade e na última fala, ao fazer uso do termo histórico "alforria", faz escapar no discurso o caráter de dominação que 0 trabalho parece exercer, apresentando o sentido de pessoas escravizadas, como descrito no dicionário eletrônico Houaiss: Alforria: "substantivo feminino:

1. Liberdade que se concede ao escravo; manumissão;
2. Derivação: por extensão de sentido. Qualquer libertação, emancipação. " Com a etimologia: "ár. al-hurríîa 'estado de homem livre, não escravo; liberdade'". Lembrando que não existem escravos, mas pessoas escravizadas, é possível extrair o sentido que o trabalho na oposição liberdade (dada pela aposentadoria) e não liberdade (dado pelo trabalho).

Dessa forma e em consonância aos estudos de Santos (1990) e Wang et al. (2011), constatou-se a percepção da aposentadoria como uma libertação das fontes de mal-estar no trabalho, como também expressa no texto: "Não tô tendo mais essa represália, não tô tendo mais esse preconceito que eu antigamente tinha, não ouço mais piada. Então eu me libertei. A aposentadoria pra mim é uma libertação". O tempo verbal do texto demarca a passagem do passado contínuo pelo gerúndio em "represália", "preconceito" e "piada" em oposição a um não passado com ausência das condições e marcado pela liberdade que a aposentadoria proporcionou. O gerúndio marca também uma ação continuada por todo o passado no trabalho que se encerra com a aposentadoria.

O termo liberdade também assume nos discursos o sentido de poder determinar o que se fazer com o seu tempo e que atividade desempenhar. Esse entendimento também foi observado em Sargent et al. (2011), correspondendo ao sentido da categoria "Tempo de relaxar", em que há um retomar do controle e da autonomia. Coerente também com essa categoria é a compreensão da aposentadoria como uma recompensa, um merecimento e um direito, vista também como um prêmio, uma conquista pela dedicação.

\section{Aposentadoria como possibilidade de ter tempo}

Outro destaque observado sobre a aposentadoria recai sobre a possibilidade de "ter tempo" o que pode ser observada em várias falas, tais como: 
1. "Eu acho que aposentadoria para mim, por enquanto, é ter mais tempo pra cuidar da saúde",

2. "Isso aí é um dos prazeres: você ter tempo para viajar, ter tempo para ficar com a família. No meu caso, prazer é você querer fazer uma coisa que você gosta mais. Agora que eu aposentei, eu viajei bem mais";

3. "Porque ele tá livre pra fazer as coisa (...) pra ele pensar e agir mais (...). Ser livre. Ter tempo. Não ser inútil. Tempo para pensar e agir". Ter tempo corresponde a uma figura de linguagem que, entre as definições apresentadas no dicionário eletrônico Houaiss, representa a "oportunidade para a realização de alguma coisa".

Assim, a fala 1 aponta para uma definição pessoal de ter mais tempo para cuidar da saúde, como uma condição transitória com a proposição "por enquanto", mas o não dito também aponta para o "não aposentado" não ter tempo para cuidar da saúde. A fala 2 traz uma associação entre 'ter tempo' e prazer, pela possibilidade de usufruir desse tempo realizando atividades que dão prazer, de uma maneira geral pelo uso do infinitivo e em seguida de maneira pessoal, pela explicação de o que é prazer. Informa a atividade que pode realizar mais vezes com a aposentadoria e o ato de 'ter tempo'. Já a fala 3 apresenta uma função para 'ter tempo', porém se distancia do objeto usando a terceira pessoa como sujeito. Este com tempo para pensar e agir, em oposição a 'não ter tempo', não pensar e não agir. Assim, a aposentadoria é ter tempo para pensar e agir, já o trabalho é não ter tempo. Portanto, é não pensar, permitindo refletir que esse discurso manifesta características alienantes do trabalho.

\section{Aposentadoria como prêmio}

Destacaram-se ainda, falas com aposentadoria significando: recompensa, prêmio ou conquista:

1. "Aposentadoria por idade é muito boa, é um prêmio, mas aposentadoria por invalidez é bem diferente";

2. "A aposentadoria foi um troféu que eu tive na minha mão",

3. "Eu defino a aposentadoria como uma conquista. Como você estuda e recebe o diploma. Então a aposentadoria é mais ou menos assim".

A fala 1 aponta para as diferenças entre aposentadorias, uma dada como prêmio e a outra não. $\mathrm{Na}$ primeira aposentadoria, o servidor é premiado, no entanto, esse sujeito está em disjunção com esse objeto, já que a aposentadoria de que desfruta não é definida por ele como um prêmio. A fala 2 aponta para o passado, no momento em que recebeu o troféu como metáfora para aposentadoria. Ainda sobre o troféu, o dicionário eletrônico Houaiss o define como: "sinal visível de uma vitória, conjunto dos despojos do inimigo derrotado". O troféu como metáfora para aposentadoria é a materialidade da vitória. A fala 3 define aposentadoria como uma conquista que pode ser considerada sinônimo de vitória, ou seja, "ato ou efeito de sair-se vencedor, de triunfar sobre um inimigo, competidor ou antagonista; triunfo", segundo o Dicionário Eletrônico Houaiss. O enunciador faz uma comparação com a conquista de um diploma. Para se adquirir um diploma é preciso estudar por anos e estar apto em todas as etapas para passar para uma nova fase, a de formado. Assim, a aposentadoria seria o resultado dos esforços empreendidos e de ter todos os requisitos para estar apto para desfrutar a nova fase.

\section{Aposentadoria como sossego}

Outros aspectos aos quais a aposentadoria foi associada referem-se ao sossego, ao descanso, à tranquilidade e à ausência de preocupação com a rotina 
laboral - sobre os quais os participantes destacam a responsabilidade de comparecer ao trabalho diariamente, o cumprimento do horário e a pontualidade. A aposentadoria também foi conotada como uma forma de libertação das más condições de trabalho e das relações socioprofissionais geradoras de mal-estar. Destacam-se:

1. "Aposentadoria pra mim, hoje é uma (...) um sossego. Um sossego. É um (...) tipo assim um parâmetro de que você não tem aquela dificuldade de ficar no trânsito, de vocêchegar no seu serviço atrasada" ou

2. "Aposentadoria é hora de descanso, de mais tranquilidade. A gente trabalhando, principalmente agente de trânsito, não tinha final de ano, não dava, porque tinha que trabalhar".

Ao representar aposentadoria como um sossego, descanso e tranquilidade os sujeitos colocam em oposição à aposentadoria o não sossego, descanso ou tranquilidade; o primeiro exemplifica com o trânsito (no caso de demoras relativas ao trânsito) e no segundo, por trabalho, inclusive, em períodos culturalmente dados ao não trabalho.

\section{Dificuldades de adaptação}

Foram encontradas, nos enunciados, dificuldades de adaptação à nova vivência demarcada pela condição de ser aposentado e dificuldade do desligamento da rotina, assim como da prática de trabalho. Situações como: preparar-se para ir trabalhar; o contracheque apontando para a realidade de aposentado; a habituação em apresentar-se como aposentado, podem ser verificadas nos discursos de alguns participantes:

1. "Eu acordava e falava: gente, eu tenho que ir trabalhar. Aí depois eu falava assim: não (...) eu tô aposentada. Aí eu pegava meu contracheque e falava assim. Não, eu tô aposentada mesmo";
2. "Eu levantava cedo pra vir trabalhar, aí meus familiares: 'Aonde você vai?' Aí que caía a ficha";

3. "Eu recebo como inspetor técnico, mas eu não sou mais, não estou mais atuando. Eu recebo como tal, que é como eu fiquei, mas eu tenho que dizer aposentada".

Tais situações remetem às dificuldades encontradas para se aposentar. A perda da rotina como um dos possíveis resultados do processo de aposentar-se, citado por Uvaldo (1995), e a imprecisão quanto à identidade e rotina - como identificado em Sargent et al. (2011), apresentam-se, neste contexto de pesquisa, pela dificuldade em desligar-se de condutas associadas ao trabalho, como assimilar a ideia de não trabalhar ou apresentar-se como aposentado, diferente de apresentarse pela anterior posição profissional.

\section{Percepção social da aposentadoria}

Acerca da imagem da aposentadoria para a sociedade, com o questionamento "como a sociedade vê o aposentado", foram realizados 23 enunciados com os significantes: estar à toa, inativo, zero à esquerda, velhice, vagabundo, falta de reconhecimento, invalidez, exclusão, fim da vida e depressão e 5 enunciados com os significantes: viajar, atividades divertidas, prêmio, merecimento, se for aposentado no serviço público está bem de vida.

\section{Inativo e inválido}

Em relação à percepção social, os termos mais representados estão no campo semântico do termo "inativo"; o dicionário traz a definição do termo dessa forma:

Que não tem atividade, que não está ativo; parado, paralisado e que não trabalha, de pouca ação; desocupado, preguiçoso, lento e por fim, diz-se de indivíduo (funcionário público, 
militar, empregado) que, por qualquer razão (aposentadoria, reforma, doença), recebe vencimentos sem exercer ativamente o trabalho. (Dicionário eletrônico Houaiss)

Ressaltam-se outras definições congruentes a essa que foram trazidas nos discursos: "zero à esquerda", "não ser nada”, "inválido”, "inútil".

1. "Inativo incomoda... é... acho mais chato esse inativo. Sou é aposentado"

2. "Eu acho que o aposentado aqui e zero a esquerda é a mesma coisa e não é desse jeito. A pessoa tem que ver quantos anos a pessoa deu aqui?"

\section{3. "Eu me considerava uma pessoa} feliz. Mas eu vejo pelo povo de fora que aposentado é igual a zero a esquerda. Eu falo pras pessoas: eu ainda estou com as minhas pernas, andando, sem depender de ninguém".

4. "Você é um inválido. Infelizmente, as pessoas verão você como sendo um inválido".

\section{5. "Todas as pessoas te veem como um} inválido. Entendeu? Não serve pra nada, é isso que eu percebo, que eu vejo nas pessoas".

6. “Eu sempre comento com as pessoas: ah, eu sou o que o Fernando Henrique falou, agora eu passei a ser vagabundo".

A fala 1 denuncia o incômodo com o termo. As falas 2 e 3 utilizam o termo "zero a esquerda", que no sentido literal - o zero a esquerda de um número - não altera o número, ou seja, sua existência é tal qual a inexistência. O sujeito, na fala 2 , tenta sustentar, pelo que já realizou, que não é 'zero a esquerda', já a fala 3 aponta para sua vida no presente como tendo independência para provar não ser 'zero a esquerda'. A fala
4 utiliza o termo inválido, que o dicionário eletrônico Houaiss define como: "o que não é válido, que não apresenta os requisitos necessários para ter valor legal; nulo; desprovido de vigor físico e moral; fraco, débil; insubsistente, vão, nulo. "Para o sujeito, as pessoas da sociedade o veem como inválido, que não serve para nada, portanto, descartável. Por fim, a fala 6 traz uma referência histórica que foi enunciada pelo, enquanto era presidente, Fernando Henrique Cardoso (FHC), e que repercute até o presente. $\mathrm{O}$ ex-presidente aposentouse aos 37 anos como professor, segundo a Folha de São Paulo, afirmou: "Fiz a reforma da Previdência para que aqueles que se locupletam da Previdência não se locupletem mais, não se aposentem com menos de 50 anos, não sejam vagabundos em um país de pobres e miseráveis" (Folha de São Paulo).

Essas concepções depreciativas relativas ao trabalhador aposentado, tais como "inutilidade, inativo, falta de reconhecimento", dialogam com o indicado por França (2003) e Santos (1990).

Nessa perspectiva, discute-se a significação do trabalhador aposentado como "inválido", como um discurso social que é apropriado por ele. $\mathrm{O}$ termo "inválido" delineia um sentido do não valor do trabalhador aposentado, propondo a ideia de que o homem é mercadoria, valorado socialmente pela força de trabalho. Na medida em que não dá a contrapartida do trabalho, perde o valor social. Esse achado é congruente com os resultados de Sargent et al. (2011) que identificaram significados semelhantes no tocante à perda de valor para a sociedade.

A relação trabalho-identidade do indivíduo (quanto à estruturação subjetiva) - como destacada por Guérin et al. (2001), Ferreira (2003), Tolfo e Piccinini (2007) e Sargent et al. (2011), bem como a hipótese do impacto da desvinculação com o trabalho sobre a identidade podem ser analisadas e problematizadas mediante os discursos verificados. Nessa intenção, 
destaca-se os sentidos que definem $o$ trabalhador aposentado como inativo, tomando a atividade laboral como um todo, não considerando a atividade laboral apenas como uma das partes e possibilidades da atividade humana, evidenciando, por conseguinte, a extensão da importância do trabalho para a sociedade e para a identidade do indivíduo. Nessa mesma lógica, o indivíduo é caracterizado como um todo pelo fato de estar em exercício de trabalho, pois quando há a retirada do aspecto trabalhador, o indivíduo desaparece.

\section{Vínculos sociais na aposentadoria}

Além desses sentidos da aposentadoria, os discursos apresentam termos como angústia, ansiedade e depressão, os quais expressam o sofrimento, conforme sugerido por Codo (1996), que não é causado pela aposentadoria em si, mas pela função social da aposentadoria. Logo, percebe-se a importância do significado social na construção dos sentidos e da realidade como proposto por Luria (1994). Possivelmente, uma parte do sofrimento da pessoa aposentada deve-se à construção social da aposentadoria.

Verifica-se uma pluralidade de concepções no tocante aos relacionamentos sociais na aposentadoria. Para alguns indivíduos, há uma perda ou diminuição dos vínculos sociais estabelecidos no trabalho anterior. Já para outros, os vínculos se mantêm. Alguns entrevistados veem na aposentadoria a oportunidade do restabelecimento de vínculos para os quais não se teve tempo em função do trabalho $\mathrm{e}$ a formação de vínculos com indivíduos que compartilham vivências semelhantes relativas à condição de aposentado. Uma fala exemplifica isso:

\footnotetext{
"Aquilo que faz falta para o aposentado é a convivência. (...). Você fica mais com as pessoas do seu serviço do que com as pessoas de casa e isso faz falta. Quando
}

você sai daqui, é restrito, não é diário. É no fim de semana. (...) Não é constante”.

Como pontuado por Wang et al. (2011), observou-se a perda e o enfraquecimento de papéis relacionados ao trabalho, como as relações socioprofissionais. Contudo, destacou-se a possibilidade de se estabelecer novos vínculos fora desse âmbito, que não eram possíveis devido ao trabalho.

\section{Velhice}

Ressalta-se que a velhice foi descrita como uma condição determinante e característica do tornar-se aposentado, tanto por via compulsória, quanto por condições incapacitantes, sendo essa última pressuposta e generalizada a outros indivíduos, desconsiderando aqueles ainda aptos para exercer as atividades laborais. A ideia de aposentadoria associada à velhice pode ser observada nas seguintes falas:

"Eu não quero passar por isso, não quero ficar igual tem um monte de velhinho lá na minha quadra, não é bem velhinho não, todos aposentados";

1. "Você tem orgulho: sou servidor público aposentado. Quando você coloca servidor fica mais confortável. Dá impressão até que o cara é mais novo".

2. "Essa palavra aposentada tem um monte de carga em cima, né? Mas é a minha situação atual. É o meu status atual, sou aposentada. Ah, é velha, é isso (...) sou aposentada."

3. "Eu associo aposentadoria à velhice. Eu imagino que quando falo às pessoas que sou aposentado, que elas pensam: você é velho. Aposentadoria é fim da vida. Aposentou, tem que esquecer, se quiser tocar sua vida, esqueça! Aposentou, acabou ali, o que espera mais da vida".

Na fala 1 , o sujeito está em disforia em relação ao objeto, rejeitando uma 
atividade que ele aponta como não sendo bem de velhinhos, mas de aposentados. Velhinho e aposentadoria entram em conjunção, na perspectiva do enunciador. $\mathrm{Na}$ fala 2, ser servidor garante que, mesmo aposentado, está mais novo. As duas falas rejeitam o sentido do envelhecimento associado à aposentadoria. Nas falas 3 e 4, os sujeitos associam aposentadoria e velhice. Na fala 4 , a velhice aponta ainda no sentido do fim da vida.

A forma como a sociedade cuida das pessoas na fase do desenvolvimento da velhice diz muito dessa sociedade, assim como aponta Beauvoir (1990). A aposentadoria, além de marcar a entrada nesta fase, deveria ser um reflexo do cuidado com essa população.

A partir dos discursos dos sujeitos, foi observado que a aposentadoria é relatada como um indicador da velhice, assim como evidenciado por Santos (1990) e Léon (1999), sendo também associada ao término da vida.

Alguns participantes significaram a aposentadoria como a aproximação da morte, término da vida, comprometimento da saúde e do corpo biológico. No entanto, há discurso que se opõe ao sentido de término da vida, indicando a realização de atividades para as quais não foi possível a concretização, devido ao tempo dedicado ao trabalho. Essa forma de pensar corrobora França et al. (2013) e Sargent et al. (2011), que também viram a aposentadoria como uma oportunidade para o engajamento em atividades não realizadas devido à dedicação às atividades laborais.

A heterogeneidade de percepções assim como reconhecida por Rodrigues et al. (2005), Wang et al. (2011) e Atchley (1999) - foi verificada nos discursos analisados, como expresso nas visões opostas referentes à aposentadoria, em que é atrelada tanto a um significado de morte, quanto à continuidade de atividades que não foram realizadas.

No que se refere à preparação para a aposentadoria, os discursos revelam uma distinção entre a expectativa e realidade: entre ter tempo e condições para fazer o que se deseja e a realidade concreta caracterizada por não saber o que fazer com o tempo dentro das novas condições financeiras. Correspondente a essa noção, os entrevistados apontam as perdas salariais, a necessidade de planejamento anterior e as limitações na saúde que podem aumentar o custo de vida.

Considerando o achado de Vaus et al. (2007) relativo à não diferenciação entre os modos de transição para a aposentadoria abrupta e gradual, assim como ao grau de controle que o indivíduo tem sobre ela, julga-se importante a condução de estudos que investiguem os efeitos dos Programas de Preparação para a Aposentadoria. Sabese que os programas consistem numa preparação gradual para o processo de aposentadoria, que consideram os fatores envolvidos e que se direcionam à tomada de consciência deles, portanto, tal fato relaciona-se ao grau de controle do indivíduo sobre esse processo.

\section{Considerações finais}

Considerando a importância do trabalho em nível individual e social, conforme preconizado por Tolfo e Piccinini (2007) e destacado por Beehr e Bennert (2007), este estudo teve por objetivo conhecer o significado da aposentadoria, por meio da percepção que o trabalhador tem sobre a aposentadoria tendo como referência a si próprio e a sociedade.

Baseando-se na definição teórica de bem-estar e mal-estar apresentada em Ferreira e Mendes (2003), este estudo amplia esta definição específica ao trabalho, avaliando os indivíduos quanto ao seu estado físico, psicológico e social referente à desvinculação com o trabalho. Designada essa especificação, pode-se observar uma predominância de mal-estar nos discursos dos aposentados sobre a imagem de si que eles percebem na sociedade. Em contrapartida, quando questionado sobre o que é a aposentadoria para o próprio sujeito, aspectos positivos diferencialmente se 
sobressaíram, caracterizando-se o bemestar.

A percepção dos aposentados concernente ao significado da aposentadoria, neste estudo, permitiu identificar alguns fatores consequentes da aposentadoria e a compreensão de como o indivíduo aposentado se avalia, contribuindo como suporte para o entendimento do processo da aposentadoria em interface com o conhecimento da ciência psicológica para o desenvolvimento de práticas prévias e posteriores, que considerem e respeitem o indivíduo e sua subjetividade como aspecto central.

\section{Referências}

Abrahão, J., Sznewar, L., Silvino, A., Sarmet, M., \& Pinho, D. (2009). Introdução à ergonomia: da prática à teoria. São Paulo: Blucher.

Atchley, R. C. (1999). Continuity and adaptation in aging: creating positive experiences. Baltimore: Johns Hopkins University Press.

Beauvoir, S. (1990). A velhice (La vieillesse). Rio de Janeiro: Nova Fronteira.

Brasilia (2011). Trabalhar com trânsito: atividades de prazer e sofrimento. Relatório de Pesquisa sobre Trabalho e Saúde. Gerência de Gestão de Pessoas, Núcleo de Qualidade de Vida, Laboratório de Psicodinâmica e Clínica do Trabalho (CPCT). DetranDF. Retirado de http://extranet.detran.df.gov.br/image s/stories/DIRIN/arquivos/RelatorioPe squisaTrabalhoSaudeDetranDF.pdf

Beehr, T. A., \& Bennett, M. M. (2007). Examining retirement from a multilevel perspective. In K. S. Shultz \& G. A. Adams (Eds.), Aging and work in the 21st century (pp. 277-302). Mahwah, New Jersey: Lawrence Erlbaum Associates (LEA).

Codo, W. (1996). Um diagnóstico do trabalho (em busca do prazer). In A.
Tamayo, J. Borges-Andrade, \& W. Codo (Orgs), Trabalho, cultura $e$ organizações (Coletâneas da Anpepp no. 11, pag. 36-55). Rio de Janeiro: Associação Nacional de Pesquisa e Pós-graduação em Psicologia. Retirado de http://www.infocien.org/Interface/Co lets/v01n11a05.pdf

Ferreira, M. C. (2003). O sujeito forja o ambiente, o ambiente "forja" o sujeito: Inter-relação indivíduoambiente em ergonomia da atividade. Em: M. C. Ferreira, S. Dal-Rosso \& A. Barbiero (Orgs.). (2003). A Regulação Social do Trabalho. Brasilia, UnB: Editora Paralelo 15, pp. 21-45.

Ferreira, M. C. \& Mendes, A. M. (2003). Trabalho e riscos de adoecimento: $o$ caso dos auditores-fiscais da Previdência Social Brasileira (Cap. 1, pp. 31-60). Brasília: Ler, Pensar, Agir.

Fiorin, J. L. (2005). Elementos da análise do discurso. São Paulo: Contexto.

Fiorin, J. L. (2012). Da necessidade da distinção entre texto e discurso. In: B. Brait. \& M.C. Souza-e-Silva (Orgs), Texto ou discurso? São Paulo: Contexto, pp 145 - 165.

Fontanille, J. (2007). Semiótica do Discurso. São Paulo: Contexto.

França, L. S. (2003). Quando o entardecer chega... o envelhecimento ainda surpreende muitos: programa de preparação para a aposentadoria. Retirado de http://www.guiarh.com.br/pp46.html

França, C. L., Murta, S. G., Negreiros, J. L., Pedralho, M. \& Carvalhedo, R. (2013). Intervenção breve na preparação para a aposentadoria. Revista Brasileira de Orientação Profissional,14 (1), pp. 99-110.

Guérin, F., Laville, A., Daniellou, F., Duraffourg, J. \& Kerguelen, A (2001). Compreender o trabalho para transformá-lo: a prática da ergonomia ( $1^{\text {a }}$ ed., G. M. J. Ingratta \& 
M. Maffei, Trad.) (Cap. 2, pp. 7-46); (Cap. 5, 79-84). São Paulo: Edgard Blücher.

Instituto Brasileiro de Geografia e Estatística [IBGE]. (2013). Projeção da População do Brasil por Sexo e Idade: 2000 - 2060. Acesso em 26 de maio de 2015 em http://www.ibge.gov.br/home/estatist ica/populacao/projecao_da_populaca $\mathrm{o} / 2013 /$ default.shtm

Leão, I.B. (1999). Os professores universitários: a emoção e o pensamento em um trabalho intelectual institucionalizado. Tese de Doutorado, PUC, São Paulo.

León, L. M. (1999). Pensando na qualidade de vida ao aposentar. Em L. A. M. Guimarães \& S. Grubits (Orgs.), Série saúde mental e trabalho (vol I). São Paulo: Casa do Psicólogo.

Luria, A. R. (1994). Curso de Psicologia Geral - Linguagem e Pensamento (Vol. 4). Rio de Janeiro: Editora Civilização Brasileira.

Minayo, M. C. S. (Org.). (2013). Pesquisa social: teoria, método e criatividade. $33^{\mathrm{a}}$ Ed. Petrópolis: Vozes.

Rodrigues, M., Ayabe, N. H., Lunardelli, M. C. F. \& Canêo, L. C. (2005). A preparação para a aposentadoria: o papel do psicólogo frente a essa questão. Revista Brasileira de Orientação Profissional, 6(1), pp. 5362.

Santos, M. F. S. (1990). Identidade e aposentadoria. São Paulo: EPU.Sargent, L. D., Bataille, C. D., Vough, H. C. \& Lee, M. D. (2011). Metaphors for retirement: Unshackled from schedules. Journal of Vocational Behaviour, 79, pp. 315324.

Sigardo, A. P. (2000). O social e o cultural na obra de Vigotski. Revista Educação \& Cultura, 71, pp. 45-78.

Tolfo, S. R., \& Piccinini, V. (2007). Sentidos e significados do trabalho: explorando conceitos, variáveis e estudos empíricos brasileiros.
Psiocologia \& Sociedade, Edição especial 1(pp. 38-46).

Uvaldo, M. C. C. (1995). Relação homemtrabalho: campo de estudo e atuação da orientação profissional. Em A. E. V. A. Güntert (Ed.) A escolha profissional em questão ( $2^{\mathrm{a}}$ ed.) (pp. 215-235). São Paulo: Casa do Psicólogo. Retirado de goo.gl/dV0RmW

Vaus, D., Wells, Y., Kendig, H. \& Quine, S. (2007). Does gradual retirement have better outcomes than abrupt retirement? Results from an Australian panel study. Ageing and Society, 667-682.

Wang, M., Henkens, K. \& Solinge, H. (2011). Retirement adjustment: a review of theoretical and empirical advancements.

American Psychologist, 66(3), 204-213.

Folha de São Paulo: http://www1.folha.uol.com.br/fsp/bra si/fc13059805.htm e http://www1.folha.uol.com.br/fsp/bra si/fc12059802.htm, acessado em 09/04/2017.

Data de submissão: 01/12/2016

Data de aceite: 13/07/2017 